\title{
Recurrent ectopic pregnancy after ipsilateral salpingectomy: a rare case report
}

\author{
Amita Yadav, Veena Gupta, Shweta Patel*
}

Department of Obstetrics \& Gynaecology, M.L.N Medical College, Allahabad, U.P., India

Received: 27 July 2015

Accepted: 14 August 2015

\author{
*Correspondence: \\ Dr. Shweta Patel, \\ E-mail: swetambbs@yahoo.co.in
}

Copyright: ( ) the author(s), publisher and licensee Medip Academy. This is an open-access article distributed under the terms of the Creative Commons Attribution Non-Commercial License, which permits unrestricted non-commercial use, distribution, and reproduction in any medium, provided the original work is properly cited.

\begin{abstract}
Ectopic pregnancy occurs in $1.3 \%$ to $2 \%$ of all pregnancies, and there is a potential threat for maternal morbidity and mortality. Ipsilateral ectopic pregnancy after partial or total salpingectomy is a rare occurrence. Current surgical management of tubal pregnancy includes conservative (usually salpingostomy) and radical (total or partial salpingectomy) methods. However, in some cases, these methods may not solve the problem. We are presenting the case of a 26 year old female G3P1+1 who presented with bleeding per vaginum, pain in abdomen, severe pallor, hypotension, and tachycardia following 3 months amenorrhoea. She had a previous right sided ruptured ectopic pregnancy and right salpingectomy done 5 years back. On laparotomy, there was right adnexal mass of $5 \times 7 \mathrm{~cm}$ size. Given the possibility of transperitonal migration of human embryos and sperm, which has a greatly increased risk associated with previous ectopic pregnancies, total salpingectomy should be the treatment of choice if conservative methods of treatment are not suitable. This case emphasizes that salpingectomy does not exclude ectopic pregnancy on the ipsilateral side. Total salpingectomy too carries the potential for the recurrence of ectopic pregnancy on the same side hence the need for clinician awareness and vigilance.
\end{abstract}

Keywords: Ectopic Pregnancy

\section{INTRODUCTION}

Ectopic pregnancy occurs in $1.3-2 \%$ of all pregnancies and women with a history of prior ectopic pregnancy have an approximately eightfold increased risk of further episodes in the future. ${ }^{1}$ The increasing incidence of ectopic pregnancy reflects a combination of factors such as earlier and more accurate diagnosis and assisted reproduction techniques. Ampullary region of the fallopian tubes is the most common site of ectopic pregnancy $(92 \%)$ followed by $2.5 \%$ in interstitial/cornual ectopic pregnancies. Current surgical management typically consists of salpingostomy, fimbrial evacuation or salpingectomy (total or partial). Ectopic pregnancy can recur in the tubal remnant stump after ipsilateral total salpingectomy. Recurrence in a patient who has had previous ectopic pregnancy is high $(8-17 \%)$ but pregnancy in remnant stump is rare, few cases have been reported and exact incidence is unknown. ${ }^{2}$

\section{CASE REPORT}

We present a case of spontaneous ectopic pregnancy occurring in the cornua of fallopian tube in a woman who had same sided salpingectomy for ruptured ectopic pregnancy 5 years back. A 26 year-old female, gravida 3, para 1, ectopic 1, was seen in the gynaecological emergency with bleeding per vaginum, pain in abdomen and vomiting for $3 \mathrm{hrs}$. following amenorrhoea of three months. Her past history revealed that she had undergone laparotomy 5 years back for a right ruptured tubal ectopic pregnancy of six weeks, for which she had a right salpingectomy. On examination her general condition was fair with moderate pallor. Her pulse rate was 100 
beats per minute and blood pressure was 100/70 $\mathrm{mmHg}$. The abdominal examination shows midline scar of previous laparotomy, abdomen was slight distended with voluntary muscle guarding and rebound tenderness. Per speculum examination showed pale vaginal mucosa and normal cervix. On per vaginal examination cervical motion tenderness was present, uterine size could not be assessed properly, no pelvic masses were felt and Pouch of Douglas was full. Culdocentesis showed non clotted blood. Her urine pregnancy test was faintly positive. Ultrasonography confirmed the absence of an intrauterine pregnancy and presence of a heterogeneous area in the right Adnexa of approximately $7 \times 5 \mathrm{~cm}$ size and free fluid in the cul-de-sac. Left adnexa and left ovary were normal. Her haemoglobin was $6.8 \mathrm{~g} / \mathrm{dl}$.

The patient was admitted, prepared and urgent laparotomy was done. Per operative Findings showed about $1.5 \mathrm{~L}$ of hemoperitoneum which was drained out. A foetus of about 13 week size along with placental tissue was taken out from abdominal cavity. Uterus was 6 weeks size; the left tube was swollen and was adhered to ovary. Right ovary and fallopian tube was not visualised. A rent of $4 \times 4 \mathrm{~cm}$ was seen in right cornual end at previous salpingectomy site, there was constant bleeding from the raw area. Haemostasis was secured at the cornual end with interrupted sutures in 2 layers by using vicryl No.1 on round bodied curve needle. Tubal ligation was done on left side. Abdominal wall was closed in layers. She was transfused total 4 units of blood and 1unit fresh frozen plasma both in per operative and postoperative period. Post-operative period was uneventful. She was discharged on the $11^{\text {th }}$ postoperative day. The clinical diagnosis of tubal ectopic Pregnancy was confirmed histologically. The tubal remnant showed immature chorionic villi and fatal parts.

\section{DISCUSSION}

Ectopic pregnancy remains an important cause of morbidity in early pregnancy; it is one of the leading causes of maternal death in the first trimester of pregnancy. The main risk factors for ectopic pregnancy include a significant history of infection, smoking, age, previous spontaneous abortions, previous infertility, and previous use of an intrauterine device. Previous medically induced abortion and ectopic pregnancy are also associated with a risk of ectopic pregnancy. ${ }^{3,4}$ Ectopic pregnancy occurring in the interstitial portion of the remnant tube following salpingectomy would be assumed to be even less common especially following spontaneous conception. The classic triad of amenorrhoea, abdominal pain and vaginal bleeding is presented in only $50 \%$ of patients with ectopic pregnancy. A proper menstrual history should be taken and urine pregnancy test should be done if required to exclude pregnancy. Any woman with a previous history of ectopic pregnancy is high risk for recurrent ectopic so high risk of suspicion should be kept. In our case, the patient has right ipsilateral ectopic pregnancy in the stump of previous ectopic site following complete salpingectomy. The mechanism by which ectopic pregnancy in the remnant tube after salpingectomy occurs is not clear. Three theories have been developed. The first proposes that contralateral fertilization occurred and the fertilized egg migrated across the endometrial cavity to the fallopian tube remnant. $^{5}$ The second suggests that in spite of a salpingectomy being performed, recanalization may occur due to inadequate diathermy allowing for passage of the ovum on the damaged side into the tubal remnant. ${ }^{6}$ The third implies that spermatozoa pass through the patent fallopian tube and travel to fertilize the ovum on the damaged side. ${ }^{7}$ Although a salpingectomy does not necessarily eradicate all ipsilateral ectopics, it certainly minimises a tubal recurrence on the same side. Appropriate measures should be taken during surgery to prevent recurrence in tubal stump which includes complete peritonisation of the cornual incision. ${ }^{3}$ Some authors also suggest cauterisation of the remaining stump. On the other hand, it is erroneous to believe that total salpingectomy is always as complete as the word implies.

\section{CONCLUSION}

This rare occurrence of ectopic pregnancy in a previously salpingectomized proximal stump of a tube is of such significance that it needs reporting. Of course, with the growing advocacy of the preservation of tubes in the management of tubal pregnancies, in particular, a rise in the incidence of recurrent ectopic pregnancies should be anticipated. At primary care level and emergency departments, urine pregnancy testing should be performed in any woman of reproductive age with unexplained per vaginal bleeding. When performing a salpingectomy, appropriate measures should be taken to prevent recurrence in tubal stump these include the length of the remnant tube should be minimised and complete peritonisation of the cornual incision to be done. We have described a situation where there was ipsilateral recurrent ectopic pregnancy, which required repeat surgical intervention. This case emphasises that total salpingectomy too carries the potential for the recurrence of ectopic pregnancy on the same side hence the need for clinician awareness and vigilance.

\section{REFERENCES}

1. Farquhar CM. Ectopic pregnancy. Lancet 2005;366:583-91.

2. Tamizian O, Arulkumaran S. Bleeding in early pregnancy. Current Obstet Gynaecol. 2004;14:2333.

3. Storeide O, Veholmen M, Eide M, Bergsjo P, Sandvei R. "The incidence of ectopic pregnancy in Hordaland county, Norway 1976-1993." Acta Obstetricia et Gynecologica Scandinavica. 1997;345-9.

4. Bouyer J, Coste J, Shojaei T, Pouly JL, Fernandez $\mathrm{H}$, Gerbaud L, et al. Risk factors for ectopic pregnancy: a comprehensive analysis based on a 
large case-control, population based study in France. Am J Epidemiol. 2003;157:185-94.

5. Y.L. Liu, K.S. Hwang, P.W. Chu, D.C. Ding. Recurrent ectopic pregnancy in the ipsilateral oviduct after prior laparoscopic partial salpingectomy, Taiwan. J. Obstet. Gynecol. 2009;417-9.

6. Samiei-Sarir B, Diehm C. Recurrent ectopic pregnancy in the tubal remnant after salpingectomy, Case Rep. Obstet. Gynecol. 2013;753269.
7. Chou SY, Hsu MI, Chow PK, Chiang HK, Su HW, Hsu CS. Recurrent ipsilateral ectopic pregnancy after partial salpingectomy, Taiwan. J. Obstet Gynecol. 2009;420-2.

Cite this article as: Yadav A, Gupta V, Patel S. Recurrent ectopic pregnancy after ipsilateral salpingectomy: a rare case report. Int $\mathrm{J}$ Reprod Contracept Obstet Gynecol 2015;4:1615-7. 